\section{Specialized Divisions}

The following information on the five Specialized Divisions approved by the Council at its Vienna meeting is taken from articles supplied by representatives of the Divisions indicated at the end of each section.

\section{Atomic Spectroscopy}

At the end of 1967, stimulated by the progress that was being made towards creating a European Physical Society, several atomic spectroscopists started to discuss the organization of better and closer cooperation between the many research groups working in Europe in the field of atomic spectroscopy and related topics.

A steering committee was formed and met in Amsterdam (March 1968) and in Caen (October 1968). At these meetings it was proposed that there should be regular - preferably annual conferences on atomic spectroscopy and related topics, to be organized in an informal and inexpensive way, in order to bring all interested people and in particular younger research students together.

It was regarded as very important to stimulate scientific exchanges between laboratories, exchanges of information, personnel, equipment, computer programmes etc., to facilitate cooperation on common research subjects and to arouse the interest of research students in the field of atomic spectroscopy. It was decided that the most efficient way of achieving this was to create a European Group for Atomic Spectroscopy (EGAS), to operate under the auspices of the European Physical Society.

These ideas met with approval from many physicists although a definite response is awaited from several Eastern European countries. Cooperation of colleagues from these countries is regarded as essential and it is hoped that they will join in the near future.

EGAS started its activities by editing a list of publications and preprints, that can now be obtained from the secretary (P.E. Noorman, Zeeman Laboratorium, Plantage Muidergracht 4 Amsterdam), and by organizing a first annual meeting in Paris, 2-5 July 1969.

At the end of the meeting a General Assembly was held, during which a Constitution was adopted and an Executive Committee elected consisting of the following members:
A. Kastler (Chairman), Paris

P.E. Noorman (Secretary), Amsterdam H. Bucka, Berlin

R. Chabbal, Orsay

D.A. Jackson, Orsay

P.F.A. Klinkenberg, Amsterdam

L. Minnhagen, Sweden

F. Rico, Madrid

G. Series, Reading

A. Steudel, Hannover.

At the invitation of A. Steudel, the next Conference will be held on 14-17 July 1970 in Hannover, Germany.

P.E. Noorman

\section{Condensed Matter}

The area of "Condensed Matter" was chosen as one which forms an effective region of physics to form a Division. Some immediate aims of the Division will be as follows :

a) Rationalization of Conferences

The Division will assist in its special area in the EPS coordination of conferences. There are a large number of meetings held in Europe at present. National Congresses covering either the whole of condensed matter or some broad area (for example, solid state devices) are held in several countries at present, some with strong participation from other countries. There is room for cooperation so that, in any one year, these meetings emphasize different areas. One of them may also be designated as the European Congress for that year, which will also permit an annual meeting of members of the Division to discuss its progress and future.

Large specialist meetings are run by IUPAP, but there are many meetings outside this framework, particularly on new topics which arouse great interest. Conferences of this type on the same topic often occur in European countries simultaneously; the Division can help by coordination and by stimulation.

Small invitation conferences have been established in Europe, following the success of the Gordon Conferences in the USA, including a Europhysics series in the area of Condensed Matter. The EPS, through its Divisions, is the obvious body to coordinate these meetings in future.

b) Summer Schools

The EPS is looking into the whole question of coordinating these schools, and the Division can help by offering technical advice.

\section{c) Personnel Services}

At present Europe has a vast number of nation-nation links in Scholarships and Fellowships, and also interlaboratory links and personal links. The arrangements are almost all bila- teral and there seems to be no impartial international organization which can be approached for advice, or which can suggest weaknesses which nations, foundations, etc. could put right. The Specialized Divisions could offer authoritative and impartial advice when needed.

To handle the work of the Division the following organization is proposed: The Division will be controlled by an organizing committee appointed for two years in the first instance. S. F. Edwards (Manchester) will be Chairman, and National Societies will be approached to suggest a delegate (or a joint delegate with other nations for smaller countries). This system has had a trial run with an ad hoc steering committee and will ensure a balance amongst the nations of Europe and, in future, a rotation of the duties which will arise. National Societies will be asked to treat the designated people as their delegates and support them in their duties. A. B. Lidiard (Harwell) will be the British delegate and has accepted the post of Secretary of the Division; it seems sensible, at least at the outset, to have Chairman and Secretary from the same country.

Any member of EPS who would like to make comments or suggestions is warmly encouraged to write to the Chairman (S. F. Edwards, Schuster Laboratory, University of Manchester, Manchester, M139PL) or Secretary.

\section{S. F. Edwards.}

\section{Low-Temperature Physics}

In the spring of 1968, C. J. Gorter, K. W. Taconis, W. J. Huiskamp and J. de Boer contacted about twenty-five physicists working in the field of low temperature physics, proposing the establishment of a "Low Temperature Physics Division". The aim was to promote in Europe the collaboration and the scientific interests of scientists engaged in this research notably in superconductivity and liquid helium research, and to organize specialized conferences, topical colloquia, summer schools, etc. on a European scale. There was an encouraging response and the proposal was discussed in a special meeting at the 11th International Low Temperature Conference in St. Andrews, Scotland, in August 1968.

At this meeting the reaction was favourable, but the opinion was expressed that there is also a danger, in creating Specialized Divisions for all fields of physics, of establishing 
barriers which damage fruitful interaction between the various fields. For this reason the word "group" was preferred over "division" so as to indicate that no dividing-up of the EPS into separate compartments was envisaged.

The tasks of the "group" were seen as to present the special interests of low temperature physics research; to collaborate with the IUPAP Commission on Low Temperature Physics (which has been active for more than twenty years in organizing the International Low Temperature Conferences held in alternate years); to organize Low Temperature Conferences or smaller specialized colloquia in Europe in particular in the years when no International Conference is organized.

Complaints were made that summer schools are regularly organized in various fields such as high energy physics, nuclear physics and solid state physics, but that low temperature physics is very much neglected. Here also is an important task in the promotion of low temperature physics.

As the EPS has only Divisions, a Division for Low Temperature Physics has been created for two years. The future development should show whether some of the Divisions would be better incorporated as "Subdivisions" in larger Divisions, or whether some other scheme avoiding duplication and division of physics in separate compartments, should be worked out. Low temperature physicists will be very much in favour of such measures as promote intensive interaction with other fields of physics because this is the basis on which low temperature physics itself flourishes.

\section{J. de Boer.}

\section{Plasma physics}

International conferences and symposia on plasma physics and its application to cosmical phenomena and controlled thermonuclear fusion have been organized with increasing frequency and on an increasing scale from the beginning of 1950. At the United Nations Conference on the Peaceful Uses of Atomic Energy in Geneva in 1958, a number of special sessions were devoted to controlled fusion research. In connection with the conference, a European CERN study group on plasma physics and thermonuclear fusion was established, which organized meetings at approximately annual intervals starting in $\mathrm{Ge}$ neva in 1958. The growing interest in and importance of plasma physics led to the meetings of the study group being transformed into a series of European Conferences on Controlled Fusion and Plasma Physics, held in Munich in 1966, in Stockholm in 1967, and in Utrecht in 1969. During the Stockholm Conference a committee of a European Plasma Physics Group was formed under the chairmanship of P. C. Thonemann.

At the Utrecht Conference the Committee decided to apply for membership as a "Plasma Physics Division" within the European Physical Society. The formation of such a Division is motivated not only by the importance of plasma physics, but also by the large resources which are involved in plasma research. For the period $1969 / 70$, the following Committee was elected at the Utrecht Conference:

B. Lehnert (Chairman), Stockholm

E. S. Weibel (Treasurer), Lausanne

C. M. Braams, Jutphaas

B. Brunelli, Frascati

R. S. Pease, Abingdon

R. Z. Sagdeev, Novosibirsk

A. Schlüter, Garching

J. Teichmann, Prague

P. C. Thonemann, Swansea

M. G. Trocheris, Fontenay-aux-

Roses

P. Vandenplas, Brussels.

The Plasma Physics Division will concern itself with the stimulation of plasma research in Europe and with scientific cooperation between institutes and laboratories of the member nations. The formation of the Division has been mainly through the initiative of fusion physicists, but it is hoped that other branches of plasma physics will also take part in the activities of the Division in the future.

\section{B. Lehnert.}

\section{Quantum electronics}

In February 1969, nine scientists from eight countries, working in the field of quantum electronics met in Berne. In order to promote further action on European cooperation in the field of Quantum Electronics the meeting established a Steering Committee:

R. Bleekrode, Eindhoven

J. Ducuing, Orsay

B. Hartmann, Stockholm

T. Jaeger, Lillestrøm

S. Kimel, Haifa

R. V. Khokhlov, Moscow

K. P. Meyer, Berne

S. A. Ramsden, Hull

D. Röss, Munich

O. Svelto, Milan.

Discussion at the Berne meeting centred on the functions and the organization of a Quantum Electronics Division of the European Physical
Society. The functions are seen as follows:

1. Promoting contacts between laboratories and scientists working in quantum electronics - exchange of preprints, collaboration on research projects, exchange of scientists, organization of colloquia.

2. Organization of small meetings on specialized topics. It was decided to have such conferences organized by a host laboratory. They will be held each July and be of approximately three days' duration. The number and frequency of the meetings could be increased if necessary.

3. Coordination of larger meetings on quantum electronics. The Division can act as a 'clearing-house' for the scheduling of meetings on quantum electronics to avoid undue overlap of subject matter and conflict of dates.

4. Compilation of a European "Who's Who in Quantum Elertronics" covering both fundamental and applied research.

5. Adoption of a journal as the European Quantum Electronics Journal preferably, a European Journal - of Applied Physics established within the framework of the unification programme under consideration by the EPS.

6. European participation at the Sixth International Quantum Electronics Conference. The Joint Council on Quantum Electronics (JCQE) will be approached to offer assistance in organizing European participation in the forthcoming meeting in Kyoto, Japan, on 7-10 September 1970.

The Steering Committee decided to organize the election of a governing board for the Division among the members of the Quantum Electronics Division by postal ballot.

Applications to participate in the activities of the Division should be sent to K. P. Meyer, Institute of Applied Physics, 3000 Bern, Sidlerstrasse 5 , Switzerland (giving name, Christian name, title, position, membership of a Physical Society or similar body).

K. P. Meyer.

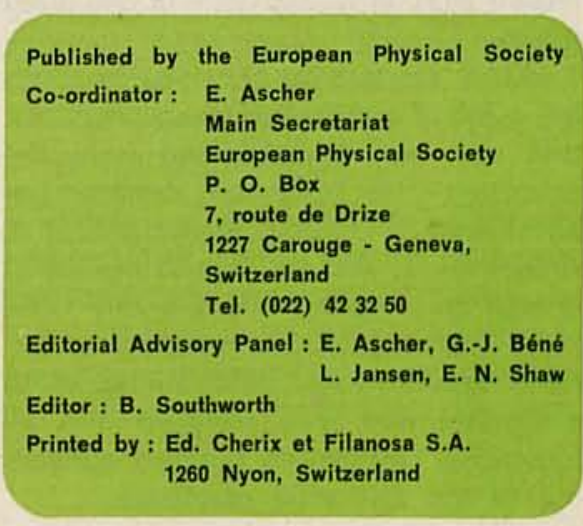

